\title{
Concordance of Treatment Recommendations for Metastatic Non-Small-Cell Lung Cancer Between Watson for Oncology System and Medical Team
}

This article was published in the following Dove Press journal: Cancer Management and Research

\author{
Hai-Sheng You $\mathbb{D}^{1, *}$ \\ Chun-Xia Gao',* \\ Hai-Bin Wang ${ }^{2}$ \\ Sai-Sai Luo' \\ Si-Ying Chen' \\ Ya-Lin Dong' \\ Jun Lyu $\mathbb{D}^{3}$ \\ Tao Tian (D) ${ }^{4}$
}

\begin{abstract}
'Department of Pharmacy, The First Affiliated Hospital of Xi'an Jiaotong University, Xi'an, Shaanxi, People's Republic of China; ${ }^{2}$ Hangzhou Cognitive N\&T. Co., Ltd, Hangzhou, Zhengjiang, People's Republic of China; ${ }^{3}$ Clinical Research Center, The First Affiliated Hospital of Xi'an Jiaotong University, Xi'an, Shaanxi, People's Republic of China; ${ }^{4}$ Department of Oncology, The First Affiliated Hospital of Xi'an Jiaotong University, Xi'an, Shaanxi, People's Republic of China
\end{abstract}

*These authors contributed equally to this work

Correspondence: Tao Tian Department of Oncology, The First Affiliated Hospital of Xi'an Jiaotong University, No. 277 West Yanta Road, Xi'an, Shaanxi 71006I, People's Republic of China

Tel +86-13572206784

Fax +86-29-85324086

Email tiantao0607@I63.com

Jun Lyu

Clinical Research Center, The First Affiliated Hospital of Xi'an Jiaotong University, No. 277 West Yanta Road, Xi'an, Shaanxi 7I006I, People's Republic of China

Tel +86298532 36/4

Fax +86298532 3473

Email lujun2006@xjtu.edu.cn
Objective: The disease complexity of metastatic non-small-cell lung cancer (mNSCLC) makes it difficult for physicians to make clinical decisions efficiently and accurately. The Watson for Oncology (WFO) system of artificial intelligence might help physicians by providing fast and precise treatment regimens. This study measured the concordance of the medical treatment regimens of the WFO system and actual clinical regimens, with the aim of determining the suitability of WFO recommendations for Chinese patients with mNSCLC.

Methods: Retrospective data of mNSCLC patients were input to the WFO, which generated a treatment regimen (WFO regimen). The actual regimen was made by physicians in a medical team for patients (medical-team regimen). The factors influencing the consistency of the two treatment options were analyzed by univariate and multivariate analyses.

Results: The concordance rate was $85.16 \%$ between the WFO and medical-team regimens for mNSCLC patients. Logistic regression showed that the concordance differed significantly for various pathological types and gene mutations in two treatment regimens. Patients with adenocarcinoma had a lower rate of "recommended" regimen than those with squamous cell carcinoma. There was a statistically significant difference in EGFR-mutant patients for "not recommended" regimens with inconsistency rate of $18.75 \%$. In conclusion, the WFO regimen has $85.16 \%$ consistency rate with medical-team regimen in our treatment center. The different pathological type and different gene mutation markedly influenced the agreement rate of the two treatment regimens.

Conclusion: WFO recommendations have high applicability to mNSCLC patients in our hospital. This study demonstrates that the valuable WFO system may assist the doctors better to determine the accurate and effective treatment regimens for mNSCLC patients in the Chinese medical setting.

Keywords: metastatic non-small-cell lung cancer, Watson for Oncology, concordance, artificial intelligence, treatment recommendations

\section{Introduction}

Lung cancer is one of the malignant tumors that seriously harms human health and has a heavy disease burden. ${ }^{1,2}$ The incidence and mortality of lung cancer worldwide rank first among all malignant tumors. ${ }^{1-3}$ The mortality rate of lung cancer is also the highest among malignant tumors in China, and there were approximately 0.73 million new cases each year. ${ }^{4}$ Non-small-cell lung cancer (NSCLC) accounts for $80-85 \%$ of cases, with $65-70 \%$ diagnosed at the metastatic stage, ${ }^{5,6}$ and the reported 5-year survival rate was only $1-5 \%{ }^{7,8}$ Most (57\%) lung cancer patients had distant metastases at the time of their initial diagnosis. ${ }^{9}$ The metastatic 
non-small-cell lung cancer (mNSCLC) patients are usually treated with chemotherapy, targeted therapies, and supportive medicine. ${ }^{10}$ Because of the molecular heterogeneity of NSCLC, up to $69 \%$ of patients with mNSCLC could have a potentially actionable molecular target, ${ }^{6,11}$ and the presence of different gene mutations could result in differences in the optimal treatment regimen. In recent years, molecular targeted therapy for mNSCLC involving the most-frequent driver genes of adenocarcinoma has become an important strategy. ${ }^{11}$

The conflict between the available medical resources and the medical needs of patients is increasing. ${ }^{12}$ With the enormous number of new antineoplastic drugs emerging and the other rapid development in the tumor field, physicians cannot keep up with the latest research findings and guidelines to better treat their patients. ${ }^{13,14}$ This situation makes it impossible to provide an appropriate treatment regimen efficiently and quickly to a specific lung cancer patient. Simultaneously, the lack of authoritative oncologists is further impeding the current situation.

It has been proposed that the above contradictions might be solved accurately and efficiently by using the Watson for Oncology (WFO) system to help oncologists to choose the appropriate treatment option for a patient within a few minutes. ${ }^{12}$ WFO combines all of the available clinical information and the latest evidence and guidelines to make informed treatment recommendations. ${ }^{13}$ WFO was introduced into China in March 2017 and is now used by many medical institutions. ${ }^{12}$ Consistency of treatment regimens between WFO and oncologists had been observed for breast cancer, lung cancer, gastric cancer, colon cancer, rectal cancer, cervical cancer, and ovarian cancer. ${ }^{12,15-17}$ However, the concordance varies significantly according to different countries and cancer types. ${ }^{12,15-17}$

There are many guidelines for NSCLC precise therapies. The commonly used clinical guidelines include the ASCO (American Society of Clinical Oncology) lung cancer guideline, National Comprehensive Cancer Network (NCCN) Clinical Practice guideline, European Society of Cancer Internal Medicine (ESMO) guideline, and Chinese Society of Clinical Oncology (CSCO) guideline. However, these national guidelines have disparate treatment details for the same disease due to national and even regional differences in drug approvals or medical policies. WFO was developed based on NCCN guidelines, whereas the treatment of lung cancer patients in China mostly follows CSCO guidelines. Although the WFO system as a new research and application field had been explored in lung cancer, ${ }^{12,15,17}$ the samples of the associated studies have been too small. In particular, there is currently inadequate information available on MNSCLC in Chinese patients.

The present study therefore selected mNSCLC for an investigation of the consistency between WFO treatment regimens and medical-team treatment regimens. This study was designed to analyze the consistency of a WFO regimen for the first-line medical treatment of mNSCLC in Chinese patients with the medical-team regimen, and determine the possible factors influencing the differences.

\section{Methods}

\section{Introduction of Our Hospital}

The First Affiliated Hospital of Xi'an Jiaotong University is one of the Chinese first Top 100 Hospitals. ${ }^{18}$ The oncology department in our hospital serves more than 30,000 cancer patients each year, and it is the largest and most comprehensive cancer treatment, teaching, and research center in Shaanxi Province. ${ }^{19}$

\section{Patient Selection}

This retrospective study included consecutive patients who received first-line therapy for mNSCLC in the First Affiliated Hospital of Xi'an Jiaotong University (Xi'an, China) between January 2016 and May 2018. This study protocol was approved by the institutional review board and included a waiver of informed consent for the anonymous collection and analysis of data. The study protocol was approved by the medical ethics committee of the Xi'an Jiaotong University Hospital (approval No. XJTU1AF2018LSK-16) and included a waiver of informed consent for the anonymous collection and analysis of data. All methods were performed in accordance with the China Food and Drug administration of principles of Good Clinical Practice (Regulation of Order No.3). Clinical data were collected on patients who received antitumor treatment, such as sex, age, pathological type, genetic mutations, and major metastatic sites. A flow diagram of patient selection process is demonstrated in Figure 1. The inclusion criteria for this study were as follows: 1) older than 18 years, 2) pathologically confirmed mNSCLC, and 3) no previous systemic therapy for metastatic disease. The exclusion criteria were as follows: 1) NSCLC diagnosed and patient examined without receiving antitumor treatment, 2) presence of metastasis in patients who had previously received antitumor treatment, 


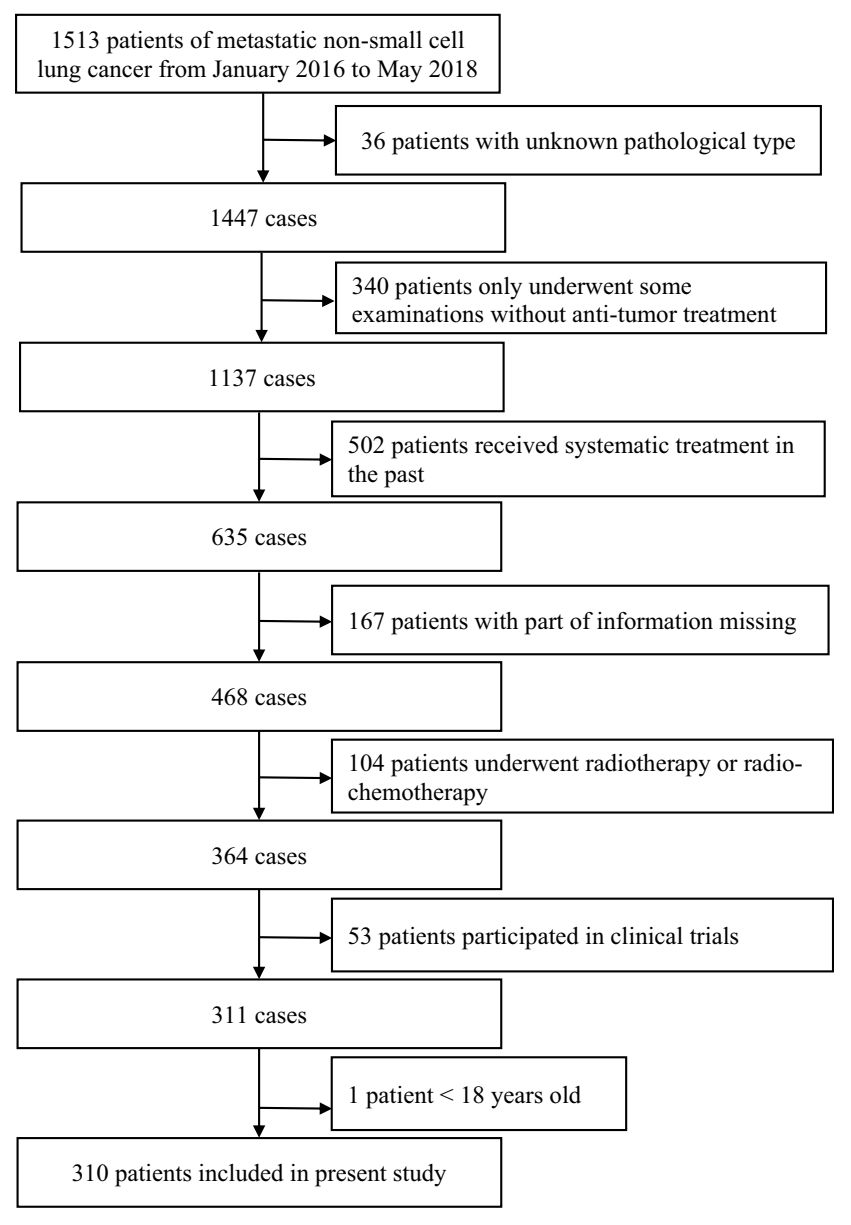

Figure I Flow diagram of metastatic non-small-cell lung cancer patient selection.

3) undergoing radiotherapy or radio-chemotherapy for NSCLC patients, 4) missing information for NSCLC patients receiving first-line treatment, or 5) being enrolled in a clinical trial.

\section{Evaluation of Consistency}

The hospital regimen was determined by the oncologist of the medical team. The medical team is composed of oncologists, radiation oncologists, pathologists, thoracic surgeons, radiologists, pharmacists, palliative care specialists, and so on. The clinical routine diagnosis and treatment process in our hospital is as follows. After patients are hospitalized, the junior doctors collect patients' data and gather the relevant experts to form the medical team. Then, the medical team develops comprehensive regimens and implements them after discussion. Patient information was collected by a study team member. The collected information was entered into WFO and documented the WFO recommended regimen by another team member. Both team members were blinded to the recommendations of the medical team. WFO treatment regimens were provided in three categories: "recommended" with a strong base of evidence, "for consideration" with that oncologists may consider a suitable alternative based on their clinical judgment, and "not recommended" with contraindications, strong evidence against their use, ${ }^{12,16}$ or recommendation of not availability. Concordance was met when the medical-team regimen was consistent with the "recommended" or "for consideration" category of the WFO system, while "not recommended" indicated discordance. WFO version 18.9 was free charged to use in this study.

\section{Data Analysis and Statistics}

Patients' information was analyzed using standard statistical software (SPSS version 23). Differences between the baseline characteristics of patients were assessed using Pearson's $\chi^{2}$ or Fisher's exact test. The factors influencing the consistency of the two treatment options were analyzed by univariate and multivariate analyses. Covariates with a p-value of less than 0.2 in a univariate analysis were entered into the multivariate analysis. OR and 95\% CI values were calculated. $P$ values less than 0.05 were considered statistically significant.

\section{Results}

\section{Characteristics of Metastatic Lung Cancer Patients}

The demographic characteristics of metastatic patients are listed in Table 1. The 310 included patients comprised 215 (69.35\%) males and 95 (30.65\%) females. There were 107 patients $(34.52 \%)$ aged at least 65 years and $203(65.48 \%)$ younger than 65 years. The proportion with adenocarcinoma was $70 \%$, while $29.34 \%$ had squamous cell carcinoma and $0.65 \%$ had large-cell carcinoma. Driver gene detection was tested in 108 patients, while revealed 77 patients with an epidermal growth factor receptor (EGFR) mutation, three patients with anaplastic lymphoma kinase (ALK) rearrangement positivity, and 28 patients with no gene mutation. The results for driver genes indicated that 80 patients $(74.07 \%)$ might have chosen tyrosine kinase inhibition as a targeted therapy. The incidence of tumor metastasis (in decreasing order) was as follows: 123 cases of lymph node metastasis throughout the body (39.68\%), 101 of pleural metastasis (32.58\%), 92 of lung metastasis $(29.68 \%)$, 91 of bone metastasis $(29.35 \%), 35$ of liver metastases $(11.29 \%)$, and 33 of brain metastasis $(10.65 \%)$. 
Table I Baseline Characteristics of Patients with Metastatic Non-Small-Cell Lung Cancer $(n=310)$

\begin{tabular}{|c|c|c|c|}
\hline Characteristic & & (n) & $\%$ \\
\hline \multirow[t]{3}{*}{ Gender } & & & \\
\hline & Male & 215 & 69.35 \\
\hline & Female & 95 & 30.65 \\
\hline \multirow[t]{3}{*}{ Age Distribution } & & & \\
\hline & $\geq 65$ & 107 & 34.52 \\
\hline & $<65$ & 203 & 65.48 \\
\hline \multirow[t]{4}{*}{ Pathological Types } & & & \\
\hline & Adenocarcinoma & 217 & 70.00 \\
\hline & Squamous cell carcinoma & 91 & 29.35 \\
\hline & Large cell carcinoma & 2 & 0.65 \\
\hline \multirow[t]{7}{*}{ Gene Mutation Status } & & & \\
\hline & EGFR common mutation & 65 & 20.97 \\
\hline & EGFR uncommon mutation & 12 & 3.87 \\
\hline & EGFR no mutation & 28 & 9.03 \\
\hline & ALK rearrangement & 3 & 0.97 \\
\hline & positivity & 202 & 6516 \\
\hline & Unknown & 202 & 65.16 \\
\hline \multirow[t]{8}{*}{ Site of Metastasis } & & & \\
\hline & Lymph node metastasis & 123 & 39.68 \\
\hline & Pleural metastasis & 101 & 32.58 \\
\hline & Lung metastasis & 92 & 29.68 \\
\hline & Bone metastasis & 91 & 29.35 \\
\hline & Liver metastasis & 35 & 11.29 \\
\hline & Brain metastasis & 33 & 10.65 \\
\hline & Others & 14 & 4.52 \\
\hline
\end{tabular}

Notes: common EGFR mutation included EGFR exon 19 deletions mutation and EGFR 21 exon mutation (L858R); uncommon EGFR mutation included EGFR exon 18 mutation (G7I9X), EGFR exon 20 insertion, and EGFR exon 18 and 20 mutation (G7I9X, S768I).

Abbreviations: EGFR, epidermal growth factor receptor; ALK, anaplastic lymphoma kinase.

\section{The Consistency of WFO and Medical- Team Recommendations}

The consistency results are presented in Figures 2 and 3. The actual treatment regimens coincided with $34.52 \%$ and $50.64 \%$ of the "recommended" and "for consideration" in WFO treatment regimens, respectively. It means that the concordance rate for both "recommended" and "for consideration" in WFO regimens reached $85.16 \%$, with a discordance rate for "not recommended" regimens accounting for only $14.84 \%$. The concordance of "recommended" rate was $19.82 \%$ and $70.33 \%$ in adenocarcinoma and squamous cell carcinoma patients, respectively, and that of "for consideration" being $67.74 \%$ and $8.79 \%$, respectively $(P<0.001$, Figure 2). Mutation of adenocarcinoma is also important factor influencing the consistency of treatment regimens
$(P<0.001$, Figure 2). There were no significant differences between the treatment regimens for gender, age ( $<65 \mathrm{vs} \geq 65$ years), ECOG score, TNM stage, or metastasis site (Figure 2).

The main pathological types of NSCLC were adenocarcinoma and squamous cell carcinoma. The overall concordance rates were $87.56 \%$ and $79.12 \%$ for adenocarcinoma and squamous cell carcinoma patients, respectively, with no significant difference (Figure 3 ). In particular, the rate of inconsistency was significantly higher $(P<0.001)$ in the two treatment regimens for the adenocarcinoma patients with detected mutation (ie, EGFR or ALK), at 18.75\% (15/80), than for the patients with no mutation detected or unknown mutation status (Figure 3).

Tables 2 and 3 present the results of the logistic regression of concordance according to patient age, gender, EOCG score, $\mathrm{T}$ stage, $\mathrm{N}$ stage, $\mathrm{M}$ Stage, pathological type, metastasis, and gene mutation. The odds ratios in Table 2 denote the odds that concordance of "recommended" will occur in a given group relative to the odds of concordance in the reference group. The "recommended" rate of the actual treatment team in WFO system and influencing factors were observed. An odds ratio of more than 1 indicates greater odds of concordance, equal to 1 shows odds equal odds, and less than 1 means lesser odds. Table 3 presents the concordance of "recommended" and "For consideration". The "recommended" and "For consideration" regimens of the actual treatment team were observed in WFO system. The odds ratios in Table 3 denote the odds that concordance of "recommended" and "For consideration".

Compared with the "for consideration" and "not recommended" of WFO treatment regimens, the univariate logistic regression analysis showed that the concordance of "recommended" regimen differed significantly for various gender, EOCG scores, N stage, pathological types, gene mutations between the two treatment regimens (Table 2). The multivariate logistic regression analysis revealed that the T stage $(P<0.05), \mathrm{N}$ stage $(P<0.05)$, pathological types $(P<0.001)$ and gene mutations $(P<0.001)$ remarkably affected consistency of the two treatment regimens. Whereas, compared with the agreement rate for concordance of "recommended" and "for consideration" regimens, there was a statistically significant difference in the "not recommended" patients of gender, gene mutation in univariate logistic regression analysis (Table 3 ). The multivariate logistic regression analysis demonstrated that 


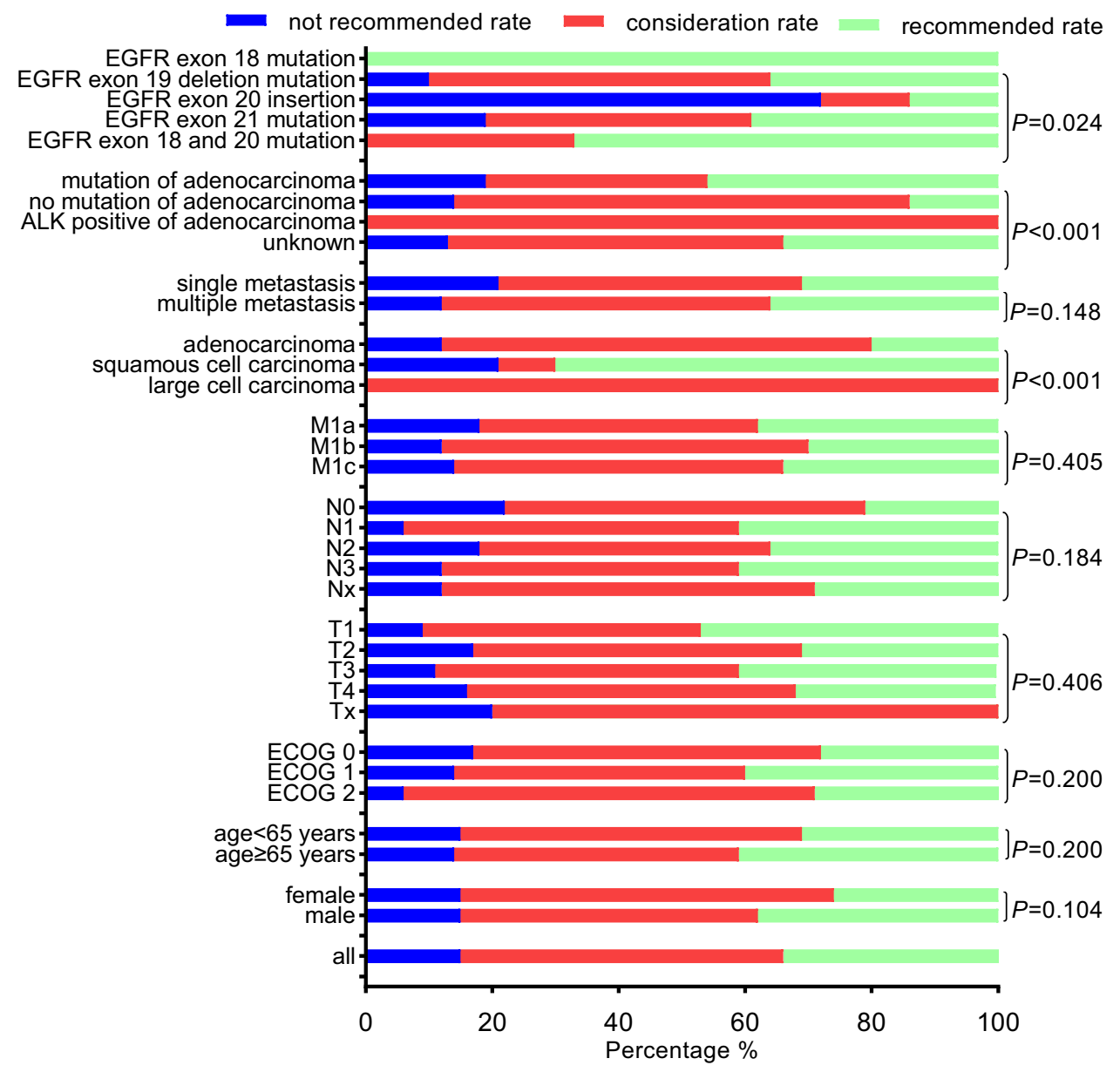

Figure 2 Consistency of Watson for Oncology regimens and medical-team recommendations in patients with metastatic non-small-cell lung cancer. Abbreviations: EGFR, epidermal growth factor receptor; ALK, anaplastic lymphoma kinase; ECOG, Eastern Cooperative Oncology Group.

various gene mutations had significantly affected concordance (Table 3).

\section{Consistency of the Influencing Factors}

Table 4 shows that these adenocarcinoma patients with EGFR mutation should have chosen osimertinib according to the WFO system, but they actually chose other targeted drugs or chemotherapy drugs. In the same situation, 3 patients with ALK rearrangement positivity should choose alectinib instead of crizotinib. For adenocarcinoma patients with no genetic mutations and unknown genetic mutations, the recommended regimens are "cisplatin combined pemetrexed plus bevacizumab" or "cisplatin combined docetaxel plus bevacizumab" in WFO system. However, these patients actually used chemotherapy regimens without bevacizumab or other similar chemotherapy regimens because of cost (Table 4 ).

There was discordance between the WFO and medical-team regimens in $10.26 \%$ of patients (4/39) with deletion mutations in exon 19 of EGFR, in $71.2 \%$ of patients $(5 / 7)$ with insertions in exon 20 , and in $19.23 \%$ of patients $(5 / 26)$ with mutations in exon 21 (Figure 2 and Table 4). The medical-team regimens are "not recommended" in the WFO, which are mainly reflected in the difference of molecularly targeted drugs (Table 4). Three patients with ALK rearrangement positivity showed consistency in the two treatment regimens.

The reasons for "for consideration" and "not recommended" regimens in 203 cases are presented in Figure 4. There were $64.53 \%$ of patients who could not afford the standard treatment because of financial burden, while $16.75 \%$ of patients $(n=34)$ chose different drugs because of the preference of their medical team, and $15.27 \%$ of patients $(n=31)$ could not obtain the drug in China. For example, nivolumab, pembrolizumab, and atezolizumab are not available in China during the study period. Inconsistency between the recommendations from the 


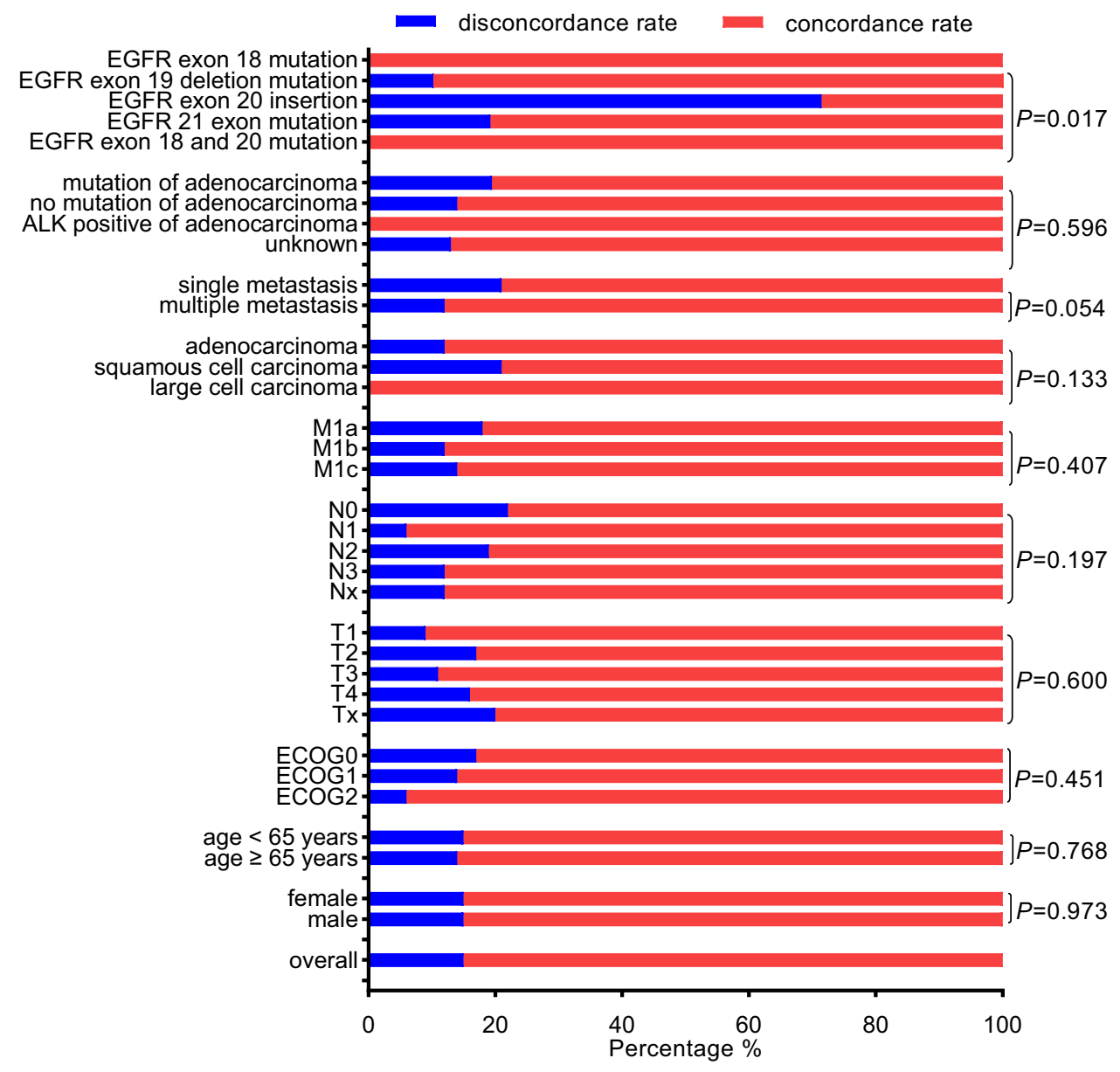

Figure 3 Concordance for metastatic non-small-cell lung cancer patients in Watson for Oncology regimens and medical-team recommendations. Abbreviations: EGFR, epidermal growth factor receptor; ALK, anaplastic lymphoma kinase; ECOG, Eastern Cooperative Oncology Group.

CSCO guidelines and NCCN guidelines accounted for $3.45 \%$ of the patients $(n=7)$.

\section{Discussion}

Patients with mNSCLC have short overall survival and poor prognosis. The main first-line systemic treatment for mNSCLC is drug therapy. ${ }^{10}$ The clinical management of NSCLC patients has evolved rapidly over the past 20 years. The clinical strategy has been based on a molecularly driven approach due to the development of targeted therapies against the driver gene mutations, which has improved the outcomes for patients. The discovery of increasing numbers of driver genes and targeted drugs has extended survival, but this also brings difficulties in clinical decision-making. Fortunately, the rapid developments in AI will powerfully support physicians in generating precise treatment regimens for patients quickly and efficiently. ${ }^{20}$ The consistency between WFO and medical-team regimens for breast cancer has been reported at $93 \%{ }^{16}$ However, the consistency between WFO and actual clinical regimens for mNSCLC in China has rarely been reported.

The total agreement rate of medical-team and WFO regimens was $85.16 \%$ (Figure 2), which was also similar to a previously reported rate of $84.6 \%$ for stage IV NSCLC patients, ${ }^{15}$ but higher than those of $61.1 \%$ reported for NSCLC patients. ${ }^{12}$ A $34.52 \%$ of the medical-team regimens were consistent with "recommended" WFO regimens, while $50.64 \%$ were consistent with the "for consideration" regimens (Figure 2), which was similar to a consistently of one-half "for consideration" options reported previously. ${ }^{15}$ The "recommended" rate of adenocarcinoma is lower than that of squamous cell carcinoma, but the "for consideration" rate is higher, because some adenocarcinoma patients did not use the preferred tyrosine kinase inhibitor recommended by WFO, chose chemotherapy regimen. Medical insurance and the low proportion of EGFR detection in China $^{21}$ were important reasons for these differences. 
Table 2 Logistic Regression of First-Line Treatment of "Recommended" versus "for Consideration" and "Not Recommended"

\begin{tabular}{|c|c|c|c|c|}
\hline \multirow[t]{2}{*}{ Variables } & \multicolumn{2}{|c|}{ Univariate Regression Analysis } & \multicolumn{2}{|c|}{ Multivariate Regression Analysis } \\
\hline & OR (95\% Cls) & $P$ value & OR (95\% Cls) & $P$ value \\
\hline \multicolumn{5}{|l|}{ Age (Years) } \\
\hline$\leq 45$ (reference) & 1.000 & & & \\
\hline $46-54$ & $0.547(0.192-1.554)$ & 0.257 & & \\
\hline $55-64$ & $0.875(0.339-2.258)$ & 0.782 & & \\
\hline$\geq 65$ & $1.262(0.488-3.268)$ & 0.631 & & \\
\hline \multicolumn{5}{|l|}{ Gender } \\
\hline Female & 1.000 & & & \\
\hline Male & $1.726(1.013-2.942)$ & 0.045 & I.78I (0.788-3.745) & 0.174 \\
\hline \multicolumn{5}{|l|}{ EOCG Scores } \\
\hline 0 & 1.000 & & & \\
\hline $\mathrm{I}$ & $1.667(1.018-2.730)$ & 0.042 & $1.749(0.9 \mid 4-3.348)$ & 0.092 \\
\hline 2 & $1.047(0.345-3.180)$ & 0.935 & $1.664(0.398-6.958)$ & 0.485 \\
\hline \multicolumn{5}{|l|}{ Stage of $T$} \\
\hline $\mathrm{T}_{1}$ & 1.000 & & 1.000 & \\
\hline $\mathrm{T}_{2}$ & $0.514(0.250-1.060)$ & 0.072 & $0.244(0.091-0.658)$ & 0.005 \\
\hline $\mathrm{T}_{3}$ & $0.79 I(0.352-1.775)$ & 0.569 & $0.233(0.075-0.722)$ & 0.012 \\
\hline $\mathrm{T}_{4}$ & $0.532(0.255-1.110)$ & 0.093 & $0.174(0.062-0.486)$ & 0.001 \\
\hline $\mathrm{T}_{\mathrm{X}}$ & ND & ND & & \\
\hline \multicolumn{5}{|l|}{ Stage of $\mathrm{N}$} \\
\hline $\mathrm{N}_{0}$ & 1.000 & & 1.000 & \\
\hline $\mathrm{N}_{1}$ & $2.474(0.97 \mid-6.303)$ & 0.058 & $4.999(|.457-| 7.15 \mid)$ & 0.011 \\
\hline $\mathrm{N}_{2}$ & $2.016(0.939-4.328)$ & 0.072 & $2.853(1.096-7.428)$ & 0.032 \\
\hline $\mathrm{N}_{3}$ & $2.489(1.201-5.161)$ & 0.014 & $5.520(2.149-14.180)$ & $<0.001$ \\
\hline $\mathrm{N}_{\mathrm{x}}$ & $1.506(0.577-3.934)$ & 0.403 & $3.258(0.946-11.213)$ & 0.061 \\
\hline \multicolumn{5}{|l|}{ Stage of $M$} \\
\hline Mla & 1.000 & & & \\
\hline MIb & $0.731(0.400-1.335)$ & 0.308 & & \\
\hline Mlc & $0.873(0.506-1.505)$ & 0.625 & & \\
\hline \multicolumn{5}{|l|}{ Pathological Type } \\
\hline Adenocarcinoma & 1.000 & & 1.000 & \\
\hline Squamous cell carcinoma and large cell carcinoma & $8.930(5.146-15.489)$ & $<0.001$ & $42.200(16.934-105.16)$ & $<0.001$ \\
\hline \multicolumn{5}{|l|}{ Site of metastasis } \\
\hline Single metastasis & 1.000 & & & \\
\hline Multiple metastasis & $1.270(0.752-2.143)$ & 0.372 & & \\
\hline \multicolumn{5}{|l|}{ Gene Mutation } \\
\hline Mutation & 1.000 & & 1.000 & \\
\hline No mutation & $0.221(0.070-0.696)$ & 0.010 & $0.051(0.012-0.222)$ & $<0.001$ \\
\hline Unknown & $0.682(0.400-1.160)$ & 0.158 & $0.069(0.026-0.179)$ & $<0.001$ \\
\hline
\end{tabular}

Abbreviations: OR, odds ratio; $\mathrm{Cl}$, confidence interval; ECOG, Eastern Cooperative Oncology Group; ND, no data.

The consensus rate was lower for patients with gene mutations than for those without gene mutations $(80.52 \%$ vs $85.71 \%$ ). The inconsistency rate was $18.75 \%$ for patients with mutations (Figure 2), which might be related to different EGFR inhibitor (icotinib) in Chinese patients ${ }^{12}$ and clinical and social factors, including medical insurance coverage. ${ }^{21}$ The prevalence of lung cancer patients with the EGFR gene mutation phenotype is higher in China $(50 \%)$ than in European and American countries (approximately $15 \%) .{ }^{22,23}$ However, the genetic detection rate of 
Table 3 Logistic Regression of First-Line Treatment of "Recommended" and "for Consideration" versus "Not Recommended"

\begin{tabular}{|c|c|c|c|c|}
\hline \multirow[t]{2}{*}{ Variables } & \multicolumn{2}{|c|}{ Univariate Regression Analysis } & \multicolumn{2}{|c|}{ Multivariate Regression Analysis } \\
\hline & OR (95\% Cls) & $P$ value & OR (95\% Cls) & $P$ value \\
\hline \multicolumn{5}{|l|}{ Age (Years) } \\
\hline$\leq 45$ (reference) & 1.000 & & & \\
\hline $46-54$ & I.160 (0.208-6.457) & 0.865 & & \\
\hline $55-64$ & $2.300(0.4|7-| 2.68 \mid)$ & 0.339 & & \\
\hline$\geq 65$ & $\mathrm{I} .400(0.27 \mathrm{I}-7.242)$ & 0.688 & & \\
\hline \multicolumn{5}{|l|}{ Gender } \\
\hline Female & 1.000 & & 1.000 & \\
\hline Male & $2.693(1.057-6.86 I)$ & 0.038 & $1.08 I(0.364-3.209)$ & 0.888 \\
\hline \multicolumn{5}{|l|}{ EOCG Scores } \\
\hline 0 & 1.000 & & & \\
\hline I & $1.273(0.490-3.304)$ & 0.620 & & \\
\hline 2 & $1.190(0.141-10.022)$ & 0.873 & & \\
\hline \multicolumn{5}{|l|}{ Stage of $\mathrm{T}$} \\
\hline $\mathrm{T}_{1}$ & 1.000 & & & \\
\hline $\mathrm{T}_{2}$ & $0.622(0.127-3.054)$ & 0.559 & & \\
\hline $\mathrm{T}_{3}$ & $1.268(0.17 \mid-9.393)$ & 0.816 & & \\
\hline $\mathrm{T}_{4}$ & $0.748(0.145-3.864)$ & 0.729 & & \\
\hline $\mathrm{T}_{\mathrm{X}}$ & $0.195(0.014-2.656)$ & 0.220 & & \\
\hline \multicolumn{5}{|l|}{ Stage of $\mathrm{N}$} \\
\hline $\mathrm{N}_{0}$ & 1.000 & & 1.000 & \\
\hline $\mathrm{N}_{1}$ & $1.667(0.316-8.778)$ & 0.547 & $1.093(0.180-5.5476 .624)$ & 0.923 \\
\hline $\mathrm{N}_{2}$ & $1.389(0.425-4.540)$ & 0.587 & $0.87 I(0.235-3.234)$ & 0.837 \\
\hline $\mathrm{N}_{3}$ & $3.704(0.891-15.398)$ & 0.072 & $4.421(0.997-19.607)$ & 0.050 \\
\hline$N_{x}$ & I.778(0.338-9.340) & 0.477 & $1.079(0.177-6.576)$ & 0.934 \\
\hline \multicolumn{5}{|l|}{ Stage of $M$} \\
\hline Mla & 1.000 & & & \\
\hline MIb & $2.165(0.557-8.423)$ & 0.265 & & \\
\hline MIc & $1.069(0.387-2.956)$ & 0.897 & & \\
\hline \multicolumn{5}{|l|}{ Pathological Type } \\
\hline Adenocarcinoma & 1.000 & & 1.000 & \\
\hline Squamous cell carcinoma and large cell carcinoma & $3.867(0.875-17.092)$ & 0.074 & $0.555(0.067-4.583)$ & 0.585 \\
\hline \multicolumn{5}{|l|}{ Site of Metastasis } \\
\hline Single metastasis & 1.000 & & & \\
\hline Multiple metastasis & $1.437(0.547-3.777)$ & 0.462 & & \\
\hline \multicolumn{5}{|l|}{ Gene Mutation } \\
\hline Mutation & 1.000 & & 1.000 & \\
\hline No mutation & $6.328(0.796-50.331)$ & 0.081 & $7.861(0.872-70.884)$ & 0.066 \\
\hline Unknown & $15.625(4.383-55.702)$ & $<0.001$ & $25.979(4.135-163.218)$ & 0.001 \\
\hline
\end{tabular}

Abbreviations: WFO, Watson for Oncology; EGFR, epidermal growth factor receptor; ALK, anaplastic lymphoma kinase.

$35 \%$ in our study is far lower than those of Tier- 1 city in China, similar to Tier-2 city and grade-1 level a general hospital in real-world practice. ${ }^{21}$ Real-world EGFR testing rates for NSCLC in North China ranged from $13.95 \%$ to $69.04 \%$ (patients treated in a Tier- 1 city). ${ }^{21}$ The EGFR test rate is just $34 \%$, ALK rearrangement positivity less than $1 \%$, PD-L1 expression almost undetected due to nonavailability of drugs during the study period. When the oncologist informed of patients about the treatment regimes, patients who could not pay for the treatment of tyrosine 
Table 4 The Medical-Team Regimens Present "for Consideration" in Watson for Oncology System ( $n=157)$

\begin{tabular}{|c|c|c|}
\hline Pathological Type Mutation Site(n) & Medical-Team Regimens(n) & $\begin{array}{l}\text { "Recommended" Regimens in } \\
\text { WFO (n) }\end{array}$ \\
\hline $\begin{array}{l}\text { Adenocarcinoma } \\
\text { EGFR exon } 18 \text { mutation (G7I9X) (I) } \\
\text { EGFR exon } 19 \text { deletions mutation(I5) } \\
\text { EGFR exon } 20 \text { insertion(I) } \\
\text { EGFR } 2 \text { I exon mutation (L858R) (I0) } \\
\text { ALK rearrangement positivity(3) } \\
\text { No Mutation(20) } \\
\text { Unknown of gene mutation(97) }\end{array}$ & $\begin{array}{l}\text { Erlotinib(I) } \\
\text { Erlotinib (2); gefitinib (I3) } \\
\text { Gefitinib (I) } \\
\text { Gefitinib (8); erlotinib (2) } \\
\text { Crizotinib (3) } \\
\text { Gemcitabine+cisplatin(3); pemetrexed+ cisplatin (8); } \\
\text { pemetrexed+carboplatin (2); pemetrexed+carboplatin } \\
\text { +bevacizumab (I); paclitaxel+ carboplatin(I); docetaxel } \\
\text { +cisplatin (5) } \\
\text { Gemcitabine+cisplatin(2); pemetrexed+ cisplatin (24); } \\
\text { pemetrexed+carboplatin (3); pemetrexed+carboplatin } \\
\text { +bevacizumab (I); paclitaxel+cisplatin (I3); paclitaxel+ } \\
\text { carboplatin(3); docetaxel+cisplatin (46); docetaxel+ } \\
\text { carboplatin(4); pemetrexed+ cisplatin + bevacizumab (I) }\end{array}$ & $\begin{array}{l}\text { Osimertinib (I) } \\
\text { Osimertinib (I5) } \\
\text { Osimertinib (I) } \\
\text { Osimertinib (I0) } \\
\text { Alectinib(3) } \\
\text { pemetrexed+ cisplatin+bevacizumab or } \\
\text { docetaxel+cisplatin + bevacizumab (20) } \\
\text { Pemetrexed+ cisplatin+bevacizumab or } \\
\text { docetaxel+cisplatin + bevacizumab ( } 97)\end{array}$ \\
\hline $\begin{array}{l}\text { Squamous Cell Carcinoma } \\
\text { Unknown of gene mutation(7) }\end{array}$ & $\begin{array}{l}\text { Gemcitabine+ carboplatin (3); docetaxel+carboplatin(2); } \\
\text { paclitaxel+ carboplatin (2) }\end{array}$ & $\begin{array}{l}\text { Paclitaxel+cisplatin; paclitaxel protein- } \\
\text { bound+cisplatin; docetaxel+cisplatin; or } \\
\text { gemcitabine+cisplatin(7) }\end{array}$ \\
\hline $\begin{array}{l}\text { Large Cell Carcinoma } \\
\text { Unknown of gene mutation(I) }\end{array}$ & Docetaxel+cisplatin (I) & $\begin{array}{l}\text { Pemetrexed+ cisplatin + bevacizumab; } \\
\text { or docetaxel+cisplatin + bevacizumab } \\
\text { (I) }\end{array}$ \\
\hline
\end{tabular}

Abbreviations: WFO, Watson for Oncology; EGFR, epidermal growth factor receptor; ALK, anaplastic lymphoma kinase.

kinase inhibitors would abandon the genetic test. Important reasons for the EGFR lower test rate could be a lack of health insurance coverage and drugs not being available in China. ${ }^{21}$ The Chinese National Essential Drugs List (2018 edition) had incorporated some oral targeted drugs including gefitinib and icotinib, which may increase the rate of gene detection and the treatment rate of patients with EGFR mutations, thereby improving the consensus rate of WFO recommendations.

Logistic regression analysis further showed that the pathological type significantly affected the agreement rate between the WFO and medical-team regimens. Gene mutations also influenced the agreement rate. Adenocarcinoma patients with a high rate of genetic mutations might lead to differences in treatment. The adenocarcinoma patients with no EGFR mutation had a lower rate of "recommended" regimens $(P<0.001$, Figure 2 and Table 2) with $14.28 \%(4 / 28)$ and a higher rate of "recommended" and "for consideration" regimens $(P=0.066$, Figure 3 and Table 3) with $85.71 \%$ (24/28). Compared to those with EGFR mutations, no-EGFR-mutation (71.42\%) and unknown-gene-mutation $(52.97 \%)$ patients mainly adopted "for consideration" recommendations rather than "recommended" regime because of the high expense of bevacizumab (Table 4). Table 3 shows gene mutation status influencing of the recommendation concordance. Osimertinib was preferred for EGFR mutation first-line medication in WFO, while the medical team chose other tyrosine kinase inhibitors due to high prices (Table 4). Therefore, the above factors were attributed to the inability to pay for expensive drugs, which had affected the patients' choice of optimal treatment.

The medical regimen recommended for 203 included patients was not the preferred option indicated by the WFO system. There were $50.64 \%$ of medical-team recommendations "for consideration" in the WFO system, and 14.84\% "not recommended" regimens (Figure 2). Figure 4 shows that $64.53 \%$ of the patients did not choose the targeted therapy for first-line treatment due to high drug prices; for example, osimertinib and bevacizumab are very expensive (Tables 4 and 5), and health insurance does not cover them. With more targeted drugs entered the Chinese 


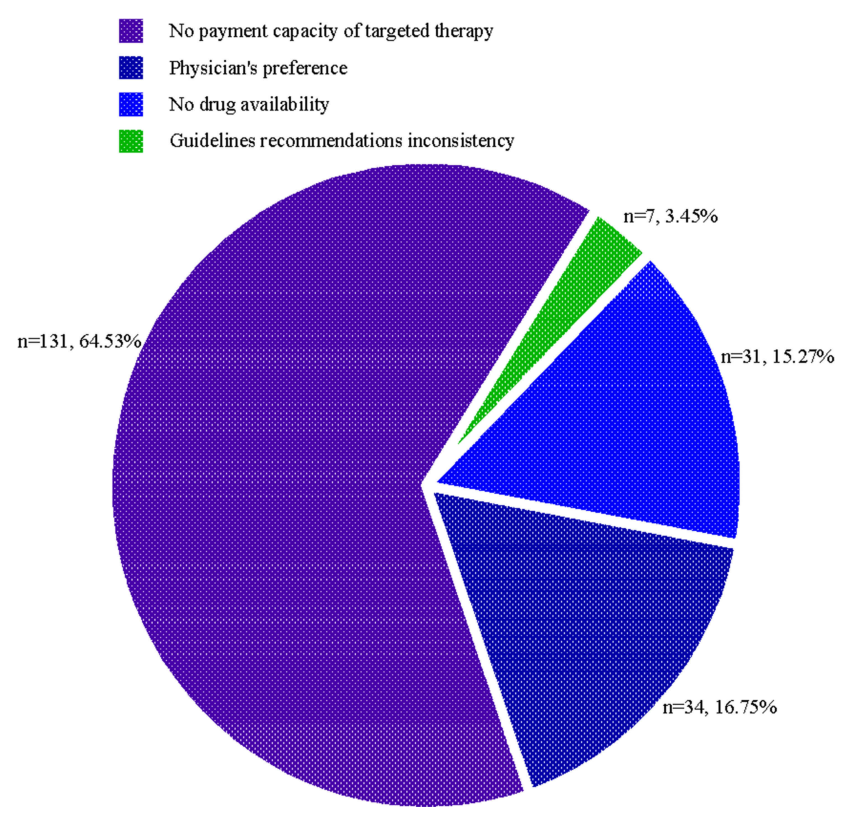

Figure 4 The reasons for "for consideration" and "not recommended" regimens in the medical-team $(n=203, \%)$.

Notes: Guidelines recommendations inconsistency indicates that medication regimens complied with the Chinese guideline but did not conform to the NCCN guideline.

National Essential Drugs List in 2019, more patients may select first-line treatment "recommended" regime of the WFO system. Meanwhile, $16.75 \%$ of the patients' medication regimens were determined by the preferences and experience of the medical team. They selected similar drugs produced in China such as paclitaxel liposomes instead of paclitaxel, lobaplatin and nedaplatin instead of cisplatin, and endostatin instead of bevacizumab (Table 4); while $15.27 \%$ of the patients in China were unable to obtain the drugs recommended by the NCCN guideline; for example, osimertinib and alectinib recommended by WFO were not available in China, immunotherapy drugs targeting PD-1 or PD-L1 such as nivolumab, pembrolizumab, and atezolizumab recommended by WFO were not available in China ${ }^{12,15}$ during the study period, and $3.5 \%$ of the patients' medication regimens complied with the Chinese guideline but did not conform to the NCCN guideline. For example, icotinib has been demonstrated to be noninferior to gefitinib (Table 4), leading to its approval in 2014 in China as a first-line treatment for patients with mEGFR-mutant NSCLC, but not approved by $\mathrm{NCCN}^{24}$ Another example is nedaplatin (Table 4), which was a first-line treatment for lung squamous cell carcinoma in the CSCO guidelines, but was not recommended by the WFO system.

WFO needs to be tested the application value in practice. The most Chinese patients used the "for consideration" regimens in Watson for Oncology system,

Table 5 The Medical-Team Regimens Present "Not Recommended" in Watson for Oncology System ( $n=46)$

\begin{tabular}{|c|c|c|}
\hline Pathological Type Mutation Site(n) & Medical Team Regimens(n) & $\begin{array}{l}\text { “Recommended" Regimens in } \\
\text { WFO (n) }\end{array}$ \\
\hline $\begin{array}{l}\text { Adenocarcinoma } \\
\text { EGFR exon } 19 \text { deletions mutation(4) } \\
\text { EGFR exon } 20 \text { insertion(5) } \\
\text { EGFR } 2 \text { I exon mutation (L858R) (6) } \\
\text { No mutation(I) } \\
\text { Unknown of gene mutation(II) }\end{array}$ & $\begin{array}{l}\text { Icotinib(2); cisplatin+docetaxel(I); trimetinib(I) } \\
\text { Crizotinib(4); icotinib(I) } \\
\text { Icotinib(5); cisplatin+docetaxel(I) } \\
\text { Paclitaxel liposomes+carboplatin(I) } \\
\text { Gefitinib(I); cisplatin(I); pemetrexed+nedaplatin(2); } \\
\text { paclitaxel liposomes+cisplatin(2); docetaxel+ lobaplatin } \\
\text { (2); paclitaxel liposomes+ lobaplatin(I); paclitaxel+ } \\
\text { lobaplatin(I); paclitaxel liposomes + carboplatin(I) }\end{array}$ & $\begin{array}{l}\text { Osimertinib(4) } \\
\text { Osimertinib(5) } \\
\text { Osimertinib(6) } \\
\text { Cisplatin+pemetrexed+bevacizumab or } \\
\text { cisplatin+docetaxel+bevacizumab(I) } \\
\text { Cisplatin+pemetrexed+bevacizumab or } \\
\text { cisplatin+docetaxel+bevacizumab(II) }\end{array}$ \\
\hline $\begin{array}{l}\text { Squamous Cell Carcinoma } \\
\text { No Mutation(3) } \\
\text { Unknown of gene mutation(16) }\end{array}$ & $\begin{array}{l}\text { Gemcitabine + nedaplatin(I); docetaxel + nedaplatin(I); } \\
\text { gemcitabine+endostatin(I) } \\
\text { Paclitaxel+cisplatin+endostatin(I); docetaxel + nedaplatin } \\
\text { (3); paclitaxel liposomes + nedaplatin(7); docetaxel } \\
\text { +losplatin(I); paclitaxel liposomes + lobaplatin (I); } \\
\text { gemcitabine + nedaplatin(I); paclitaxel + lobaplatin (I); } \\
\text { paclitaxel + nedaplatin(I) }\end{array}$ & $\begin{array}{l}\text { Gemcitabine+cisplatin; paclitaxel(albumin } \\
\text { bound)+cisplatin; cisplatin+paclitaxel; or } \\
\text { cisplatin+docetaxel(3) } \\
\text { Gemcitabine+cisplatin; paclitaxel(albumin } \\
\text { bound)+cisplatin; cisplatin+paclitaxel; or } \\
\text { cisplatin+docetaxel(16) }\end{array}$ \\
\hline
\end{tabular}

Abbreviations: WFO, Watson for Oncology; EGFR, epidermal growth factor receptor; ALK, anaplastic lymphoma kinase. 
which are also alternative treatment regimens in NCCN guidelines rather than the preferred regimes. Although some patients are unable to use WFO's first-line regimen due to payment, the "for consideration" regimens were very meaningful for the treatment of the Chinese patients. The results of this study are also an advantage of further improving the medical behavior of clinicians in China. If some drugs with lower cost produced by Chinese pharmaceutical factory or recommended by the CSCO guidelines were incorporated WFO system in the Chinese medical setting, which will also significantly improve the consistency of treatment, such as paclitaxel liposomes, icotinib, endostatin, nedaplatin, etc. Therefore, further researches of the WFO system should be improved with including Chinese guideline recommendations, and it will promote the WFO system widespread clinical use in China.

\section{The Limitations in the Study}

There are several limitations in the present study. Firstly, this study is a single-center retrospective observational study without controls. Then, we will further conduct prospective studies to test the application value of WFO in practice. Secondly, our research time is later than clinical practice and guidelines updates, which also reduces the rate of agreement. Thirdly, the molecular detection rate of the study is far lower than those of Tier-1 city in China, which may reduce the consistency of the treatment regimens. Although the present study existed above limitations, our center is the highest level of tertiary hospital in the northwest of China, and this research has a certain representativeness in real practice.

\section{Conclusion}

The treatment regimens of a medical team for mNSCLC exhibited an agreement rate of $85.16 \%$ with the WFO regimens in our treatment center, which shown that WFO has high suitability to mNSCLC patients in our hospital. WFO system may assist doctors better to determine the accurate and effective treatment regimens for mNSCLC patients in the Chinese medical setting. The pathological type and gene mutations markedly influence the agreement rate of the two treatment regimens. The presence or absence of consistency between the two regimens was affected by drug price, drug availability, the ability of patients to pay, physician preferences, and various guidelines for mNSCLC patients in our hospital. If the WFO system is improved in the Chinese medical setting, which would better support physicians' decisions accurately and efficiently.

\section{Acknowledgments}

This study was supported by the National Social Science Foundation of China (No.16BGL183), the Clinical Research Award of the First Affiliated Hospital of Xi'an Jiaotong University, China (No. XJTU1AF-CRF-2016021), and the Science and Technology Development of Shaanxi Province, China (No.2017SF-089).

\section{Author Contributions}

All authors contributed to data analysis, drafting or revising the article, gave final approval of the version to be published, and agree to be accountable for all aspects of the work.

\section{Disclosure}

The authors declare that they have no competing interests.

\section{References}

1. Bray F, Ferlay J, Soerjomataram I, et al. Global cancer statistics 2018: GLOBOCAN estimates of incidence and mortality worldwide for 36 cancers in 185 countries. CA Cancer J Clin. 2018;68:394-424. doi:10.3322/caac.v68.6

2. Fitzmaurice C, Akinyemiju TF, Al Lami FH, et al. Global, regional, and national cancer incidence, mortality, years of life lost, years lived with disability, and disability-adjusted life-years for 29 Cancer Groups, 1990 to 2016: a systematic analysis for the Global Burden of Disease Study. JAMA Oncol. 2018;4(11):1553-1568. doi:10.1001/ jamaoncol.2018.2706

3. McErlean A, Ginsberg MS. Epidemiology of lung cancer. Semin Roentgenol. 2011;46(3):173-177. doi:10.1053/j.ro.2011.02.002

4. Chen W, Zheng R, Baade PD, et al. Cancer statistics in China, 2015. CA Cancer J Clin. 2016;66(2):115-132. doi:10.3322/caac.21338

5. Ansari J, Re S, El-osta H. Epigenetics in non-small cell lung cancer: from basics to therapeutics. Transl Lung Cancer Res. 2016;5(2):155171. doi:10.21037/tlcr.2016.02.02

6. Reck M, Heigener DF, Mok T, Soria JC, Rabe KF. Management of non-small-cell lung cancer: recent developments. Lancet. 2013;382 (9893):709-719. doi:10.1016/S0140-6736(13)61502-0

7. Mountain CF. Revisions in the international system for staging lung cancer. Chest. 1997;111(6):1710-1717. doi:10.1378/chest.111. 6.1710

8. Lin WC, Chiu CH, Liou JL, et al. Gefitinib as front-line treatment in Chinese patients with advanced non-small-cell lung cancer. Lung Cancer. 2006;54(2):193-199. doi:10.1016/j.lungcan.2006.07. 013

9. Shi Y, Sun Y, Yu J, et al. China experts consensus on the diagnosis and treatment of advanced stage primary lung cancer (2016 version). Zhongguo Fei Ai Za Zhi. 2016;19(1):1-15. doi:10.3779/j.issn.10093419.2016.01.01

10. Fang B, Mehran RJ, Heymach JV, Swisher SG. Predictive biomarkers in precision medicine and drug development against lung cancer. Chin J Cancer. 2015;34(3):295-309. doi:10.1186/s40880-015-0028-4 
11. Hirsch FR, Scagliotti GV, Mulshine JL, et al. Lung cancer: current therapies and new targeted treatments. Lancet. 2017;389 (10066):299-311. doi:10.1016/S0140-6736(16)30958-8

12. Liu C, Liu X, Wu F, et al. Using artificial intelligence (Watson for Oncology) for treatment recommendations amongst Chinese patients with lung cancer: feasibility study. J Med Internet Res. 2018;20(9): e11087. doi:10.2196/11087

13. Doyle-lindrud S. Watson will see you now: a supercomputer to help clinicians make informed treatment decisions. Clin J Oncol Nurs. 2015;19(1):31-32. doi:10.1188/15.CJON.31-32

14. Curioni-fontecedro A. A new era of oncology through artificial intelligence. ESMO Open. 2017;2(2):e000198. doi:10.1136/esmoopen-2017-000198

15. Zhou N, Zhang CT, Lv HY, et al. Concordance study between IBM Watson for Oncology and clinical practice for patients with cancer in China. Oncologist. 2018;23:1-8.

16. Somashekhar SP, Sepulveda MJ, Puglielli S, et al. Watson for oncology and breast cancer treatment recommendations: agreement with an expert multidisciplinary tumor board. Ann Oncol. 2018;29(2):418423. doi:10.1093/annonc/mdx781

17. Suwanvecho S, Suwanrusme H, Sangtian M, et al. Concordance assessment of a cognitive computing system in Thailand. J Clin Oncol. 2017;35(15_suppl):6589. doi:10.1200/JCO.2017.35.15_suppl. 6589
18. JDYFY. Introduction of the First Affiliated Hospital of Xi'an Jiaotong University. Chinese; 2018 Mon.

19. JDYFY. Introduction of oncology department of the First Affiliated Hospital of Xi'an Jiaotong University. Chinese; 2018 Mon.

20. Jiang F, Jiang Y, Zhi H, et al. Artificial intelligence in healthcare: past, present and future. Stroke Vasc Neurol. 2017;2(4):230-243. doi:10.1136/svn-2017-000101

21. Cheng Y, Wang Y, Zhao J, et al. Real-world EGFR testing in patients with stage IIIB/IV non-small-cell lung cancer in North China: A multicenter, non-interventional study. Thorac Cancer. 2018;9 (11):1461-1469. doi:10.1111/tca.2018.9.issue-11

22. Zhou C. Lung cancer molecular epidemiology in China: recent trends. Transl Lung Cancer Res. 2014;3(5):270-279. doi:10.3978/j. issn.2218-6751.2014.09.01

23. Li T, Kung HJ, Mack PC, Gandara DR. Genotyping and genomic profiling of non-small-cell lung cancer: implications for current and future therapies. J Clin Oncol. 2013;31(8):1039-1049. doi:10.1200/ JCO.2012.45.3753

24. Shi Y, Zhang L, Liu X, et al. Icotinib versus gefitinib in previously treated advanced non-small-cell lung cancer (ICOGEN): a randomised, double-blind Phase 3 non-inferiority trial. Lancet Oncol. 2013;14(10):953-961. doi:10.1016/S1470-2045(13)70355-3

\section{Publish your work in this journal}

Cancer Management and Research is an international, peer-reviewed open access journal focusing on cancer research and the optimal use of preventative and integrated treatment interventions to achieve improved outcomes, enhanced survival and quality of life for the cancer patient.
The manuscript management system is completely online and includes a very quick and fair peer-review system, which is all easy to use. Visit http://www.dovepress.com/testimonials.php to read real quotes from published authors. 